\title{
Carbon Emission Allocation and Efficiency of EU Countries*
}

\author{
Ming-Chung Chang \\ Department of Banking and Finance, Kainan University, Taiwan, China \\ Email: changmc@mail.knu.edu.tw
}

Received June 2, 2012; revised July 1, 2012; accepted July 10, 2012

\begin{abstract}
Reduction of $\mathrm{CO}_{2}$ emissions is increasingly important among countries that want to protect the environment against global warming and climate change. This study examines two methods of $\mathrm{CO}_{2}$ emission reduction $-\mathrm{CO}_{2}$ emission allowance and an international agreement-by applying the Zero Sum Gains Model and the Cooperation and Alliance Model. We conclude that all DMUs reach $100 \%$ efficiency after trading on the $\mathrm{CO}_{2}$ emission allowance. The international agreement also improves the average efficiency of all DMUs, but its effect is inferior to the trading of the $\mathrm{CO}_{2}$ emission allowance.
\end{abstract}

Keywords: $\mathrm{CO}_{2}$ Emission Allowance; International Agreement

\section{Introduction}

An excess of greenhouse gas (GHG) emissions has caused the global climate change that is now threatening global ecosystems and impacting human existence. For the sustainability of earth and human life, restoring and safeguarding the environment has received much attention recently. Carbon dioxide $\left(\mathrm{CO}_{2}\right)$ is one GHG and controlling its emissions has been ardently regulated by the mechanisms of Clean Development Mechanism (CDM), Joint Implementation (JI), and Emission Trading (ET) in the Kyoto Protocol.

The European Union has established the European Union Emission Trading Scheme (EU ETS) by Directive 2003/87/EC for GHG emission allowance trading. The first phase of the scheme was from 1 January 2005 to 31 December 2007 and set up $\mathrm{CO}_{2}$ emission regulation in the EU's 25 member states. Under the scheme, energy-incentive industries and industries with a thermal capacity of 20 MW or more must hold a GHG emission permit to legally emit GHG. Each member state's National Allocation Plan (NPA) draws up an emission amount of GHG and submits the draft to the European Commission for approval.

The feature of the EU ETS allowance in the first phase includes a grandfathering principle, a benchmarking principle, and an auctioning principle. In the grandfathering principle, the member states obtain an emission allow-

*The author appreciates the part of financial support from National Science Council (NSC 100-2410-H-424-019-). ance based on a post emission record. In the benchmarking principle, the EU ETS allocation rules consider the member states' production technology and specific production inputs and outputs. The auctioning principle is for member states to bid on a $\mathrm{CO}_{2}$ emission allowance. Sijm et al. analyze and compare the advantages and disadvantages among the three regulations for carbon credit allocation and conclude that the auctioning regulation is the best rule to fit economic efficiency [1].

The main objective of our paper is to propose two alternative $\mathrm{CO}_{2}$ emission allowance allocation models. We introduce the Zero Sum Gains Data Envelopment Analysis (ZSG-DEA) model and the Cooperation and Alliance (CA) model to reallocate the $\mathrm{CO}_{2}$ emission allowance. Both models are applied in our paper to estimate the performances of decision making units (DMUs) given the total amount of $\mathrm{CO}_{2}$ emission required by the European Commission. Based on the data provided by the Community Independent Transaction Log (CITL), the approved $\mathrm{CO}_{2}$ emission allowances are about 200 million tons from 2005 to 2007.

The most seminal DEA model, popularly known as DEA CCR, is proposed by Charnes et al. [2]. It applies a non-parametric analysis method for evaluating the relative efficiency of DMUs based on the proportion of inputs and outputs. The DEA method has been applied in many various fields such as education, health care, and banking for improving and monitoring DMUs' performance. It is widely-known that an efficiency estimation is usually based on the assumptions that 1 ) Inputs need to 
be minimized and outputs need to be maximized; and 2) Inputs and outputs are isotonic variables; which means that inputs and outputs are "good" or called desirable variables [3]. However, both desirable (good) and undesirable (bad) variables may be simultaneously present. The concept of an undesirable output has been already mentioned in the seminal work of Koopmans in that pollutants (bad) may be generated in an inefficient production process when the final products (good) are manufactured [4]. The output of pollutants is undesirable and it is an anti-isotonic variable.

An undesirable output, which is an inefficient productive result, should be minimized to improve performance. Scheel uses DEA models that include undesirable outputs to discuss issues surrounding environmental performance [5]. There are three approaches to treat the undesirable output variables in a DEA context: 1) Let the reciprocal of the undesirable output be the DEA output [5-7]; 2) Transform the undesirable output to be the negative numbers and then use them as the DEA input; [5,8]; 3) View the undesirable output as the input variable [9-11]. However, we must stress that the third approach is not approved by Seiford and Zhu since "if one treats the undesirable outputs as inputs, the resulting DEA model does not reflect the true production process (Seiford and Zhu, 2002, p. 17)” [12]. Similarly, Färe and Grosskopf also point out some drawbacks when treating undesirable outputs as inputs [13]. Although the $\mathrm{CO}_{2}$ emission is an undesirable output, the $\mathrm{CO}_{2}$ emission allowance, which is the key role in our study, is an indispensible input factor in the regime of EU ETS whereby the amount of $\mathrm{CO}_{2}$ emission allowance is also limited by the European Commission. In this paper we propose the ZSG-DEA model to analyze the issue of $\mathrm{CO}_{2}$ emission allowance.

Marcos et al. provide a theoretical framework of the ZSG-DEA model to analyze the performance of participant countries in the Olympics in accordance with the number of medals they have won [14]. The ZSG-DEA model requires that the total number of medals to be won is constant. The ZSG-DEA model is also applied in the field of environmental economics. Sachs uses the ZSGDEA model in an ecological economy that provides a limitation on pollutants' emission [15]. Gomes and Lins use the ZSG-DEA model to consider $\mathrm{CO}_{2}$ emission trade in which $\mathrm{CO}_{2}$ emissions are viewed as an undesirable output [10]. In our paper we also apply the ZSG-DEA model and view the $\mathrm{CO}_{2}$ emission allowance as a desirable input. Moreover, we propose examining the allocation of $\mathrm{CO}_{2}$ emission allowance for the 25 member states in the EU.

\section{Model Set-Up}

To formally present our calculation process, we consider a set with $r$ DMUs. Each DMU uses $t$ inputs to manufacture $s$ outputs. We define $x_{k}^{i}$ as the amount of input $k$ and $y_{j}^{i}$ as the amount of input $j$ for DMU $i$, where $k=1, \cdots, t, j=1, \cdots, s$, and $i=1, \cdots, g, \cdots r$.

\subsection{DEA CCR Model}

According to the classical DEA CCR model, a measure of the relative efficiency of DMU $g$ is defined as the ratio of a weighted sum of its outputs to a weighted sum of its inputs. The optimal efficient value is obtained by treating weights as variables and by maximizing the efficiency ratio of DMU $g$ subject to the constraint that other DMUs' efficiency ratio is larger than 1 given the same set of weights. The following model is the relative efficiency value of DMU $g$ under input orientation:

$$
\begin{aligned}
& e^{g}=\max \frac{\sum_{j=1}^{s} u_{j} y_{j}^{g}}{\sum_{k=1}^{t} v_{k} x_{k}^{g}} \quad \text { s.t. } \frac{\sum_{j=1}^{s} u_{j} y_{j}^{g}}{\sum_{k=1}^{t} v_{k} x_{k}^{g}} \leq 1, i=1, \cdots, r \\
& u_{j}, v_{k} \geq 0 \text { for } \forall j, k,
\end{aligned}
$$

where $u_{j}$ and $v_{k}$ are the weights of output and input, respectively.

\subsection{ZSG-DEA Model}

In the regime of EU ETS, the $\mathrm{CO}_{2}$ emission allowance is viewed as "good" and as a limited input factor. We define $z^{i}$ as the amount of $\mathrm{CO}_{2}$ emission allowance for DMU $i$, and $\bar{z}=\sum_{i=1}^{r} z^{i}$. Based on the framework of the DEA CCR model, the relative efficiency of DMU $g$ under the input orientation is obtained from the ZSG-DEA model as follows:

$$
\begin{aligned}
& e^{g}=\max \frac{\sum_{j=1}^{s} u_{j} y_{j}^{g}}{\bar{z}-\sum_{\substack{i=1 \\
i \neq g}}^{r} z^{i}} \quad \text { s.t. } \frac{\sum_{j=1}^{s} u_{j} y_{j}^{g}}{\bar{z}-\sum_{\substack{i=1 \\
i \neq g}}^{r} z^{i}} \leq 1, i=1, \cdots, r \\
& u_{j} \geq 0 \text { for } \forall j .
\end{aligned}
$$

The fractional model in Equation (2a) can be rewritten as a linear programming model by scaling the denominator in the objective function to be 1 . The linear programming model in the input orientation is:

$$
\begin{aligned}
& e^{g}=\max \sum_{j=1}^{s} u_{j} y_{j}^{g} \quad \text { s.t. } \bar{z}-\sum_{\substack{i=1 \\
i \neq g}}^{r} z^{i}=1 \\
& \sum_{j=1}^{s} u_{j} y_{j}^{i}-\bar{z}-\sum_{\substack{i=1 \\
i \neq g}}^{r} z^{i} \leq 0, i=1, \cdots, r \\
& u_{j} \geq 0 \text { for } \forall j .
\end{aligned}
$$




\section{A Reallocation of $\mathrm{CO}_{2}$ Emission Allowance in the $\mathrm{EU}$}

\subsection{Data Description}

In the previous literature, Gomes and Lins use $\mathrm{CO}_{2}$ emissions as the input, while population, energy consumption, and gross domestic product (GDP) are used as outputs [10]. In order to follow the isotonicity in classical DEA models, we consider here the $\mathrm{CO}_{2}$ emission allowance as the input and the GDP as the output to reallocate the $\mathrm{CO}_{2}$ emission allowance for 25 member states in the EU. We refer to the 2007 data published by the CITL for the $\mathrm{CO}_{2}$ emission allowance (in ton ${ }^{3}$ of equivalent carbon) and the World Bank Database for GDP (in USD).

\section{2. $\mathrm{CO}_{2}$ Emission Allowance Model: ZSG-DEA Model}

The reason for proposing the use of the ZSG-DEA model is to have an efficient allocation on the $\mathrm{CO}_{2}$ emission allowance while having all countries be on the efficiency frontier. By refining Equation (2b), the ZSG-DEA model for 25 member states in the EU is given $i=1, \cdots, 25 ; j=1$ :

$$
\begin{aligned}
& e^{g}=\max y^{g} \\
& \text { s.t. } h\left(\bar{z}-\sum_{\substack{i=1 \\
i \neq g}}^{25} z^{i}\right)=1 \quad y^{i}-h\left(\bar{z}-\sum_{\substack{i=1 \\
i \neq g}}^{25} z^{i}\right) \leq 0, h \geq 0 .
\end{aligned}
$$

From Equation (3), we obtain a DEA frontier that represents a fair allocation of the $\mathrm{CO}_{2}$ emission allowance in which all countries lie uniformly on the DEA frontier.

In Table 1 there is only one efficient DMU in the DEA CCR model: Sweden allocates $1.099 \%$ to the total $\mathrm{CO}_{2}$ emission allowance. The average efficiency value for all DMUs is 36.3\%. Consider the case between Denmark and Greece in that they have almost the same GDP, but the $\mathrm{CO}_{2}$ emission allowance of Denmark is less, which creates a higher efficiency value relative to Greece. Similarly, Poland and Sweden both have almost the same GDP, but the $\mathrm{CO}_{2}$ emission allowance of Sweden is far less than that of Poland, which causes a higher efficiency value relative to Sweden.

Table 1. Data, DEA CCR efficiency, and optimal allocation by the ZSG-DEA model.

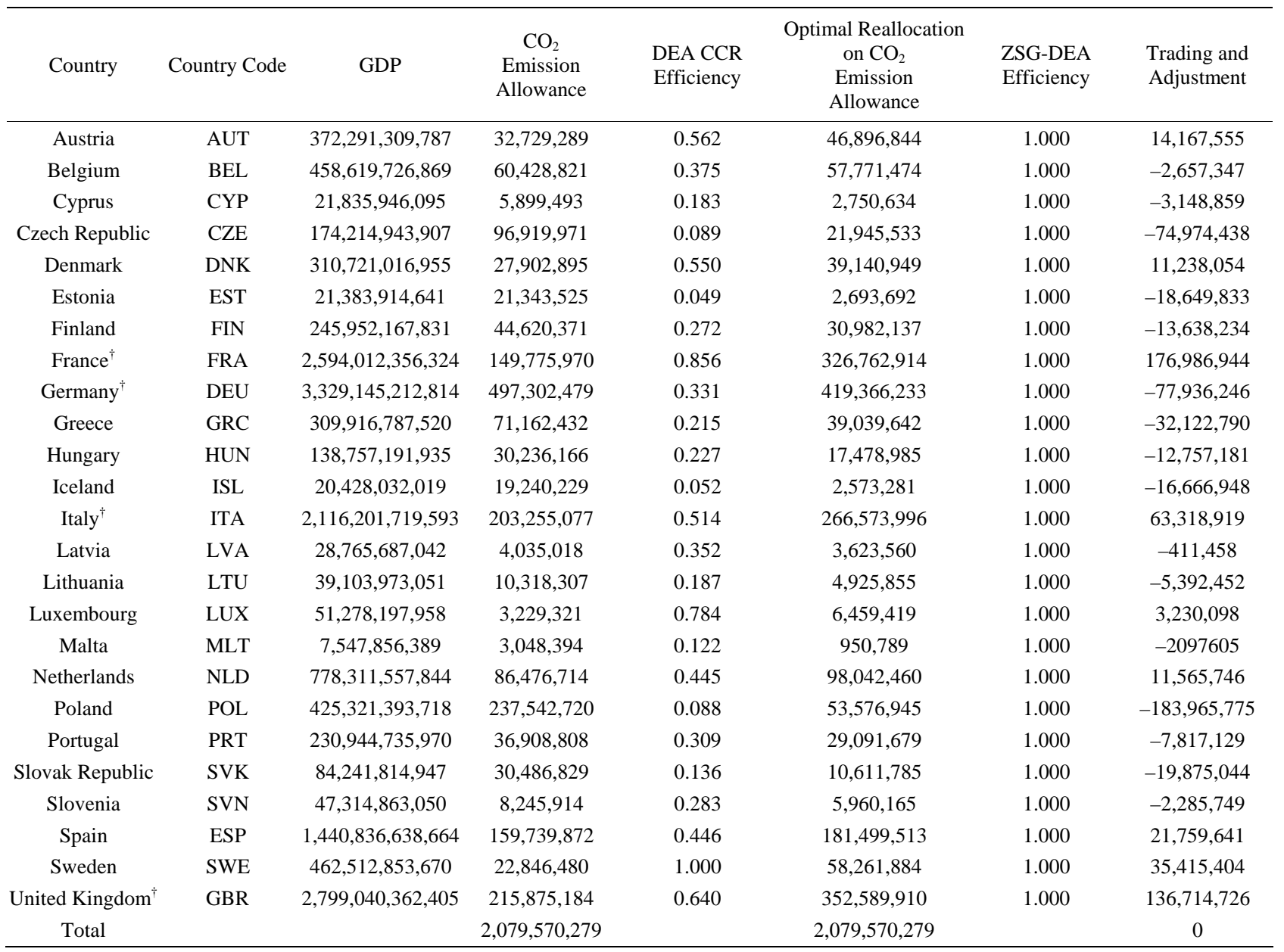

${ }^{\dagger} \mathrm{EU}$ state is in the G8. 
Using the ZSG-DEA model, we redistribute the $\mathrm{CO}_{2}$ emission allowance (Table 1, Column 6) to make all DMUs become 100\% efficient (Table 1, Column 7). The numbers in the final column of Table $\mathbf{1}$ can be seen as the feasible trade quota of $\mathrm{CO}_{2}$ emission allowance. If some countries aim to become $100 \%$ efficient, then they can purchase or sell their $\mathrm{CO}_{2}$ emission allowance. For example, France, Italy, and the United Kingdom in the Group of Eight (G8) need more $\mathrm{CO}_{2}$ emission allowance to improve performance ${ }^{1}$; however, Germany is also a member of G8, ret needs to decrease $\mathrm{CO}_{2}$ emissions to increase efficiency. Under the restricted $\mathrm{CO}_{2}$ emission allowance, countries that can increase their emissions must trade with others that need to reduce their emissions. We also see that $\mathrm{CO}_{2}$ emissions are allowed to increase in only 9 countries among the 25 EU members. From a social regulator's viewpoint, a country with a high (low) GDP should be allocated more (less) $\mathrm{CO}_{2}$ emission allowance.

In Figure 1 we find the DEA CCR frontier is located on the right of the ZSG-DEA frontier. The reason for the frontier in the DEA CCR model shifting to the right is that the restriction in the ZSG-DEA model is more than that in the DEA CCR model. Many EU member states are concentrated in the southwest part of Figure 1. This means these countries have a lower GDP and less $\mathrm{CO}_{2}$ emission allowance. On the contrary, a few EU member states are located in the northeast part of Figure 1, such as the United Kingdom, Germany, France, and Italy, which all belong to the G8. These countries have a higher GDP and more $\mathrm{CO}_{2}$ emission allowance. This phenomenon shows that a country with a higher GDP will be allocated more $\mathrm{CO}_{2}$ emission allowance. However, the amount of $\mathrm{CO}_{2}$ emission allowance held by each state before trading cannot result in $100 \%$ efficiency. Hence, only Sweden is located on the DEA CCR frontier before trading. A surplus or deficit $\mathrm{CO}_{2}$ emission allowance can be respectively sold or obtained in the regime of the EU ETS. After trading and reallocating the $\mathrm{CO}_{2}$ emission allowance, each state shifts to the frontier of the ZSG-DEA model, which means that each state reaches $100 \%$ efficiency after the reallocation of $\mathrm{CO}_{2}$ emission allowance.

\section{3. $\mathrm{CO}_{2}$ Emission Allowance Model: CA Model}

There were 15 EU members in 1995. Based on the objective of the Kyoto Protocol, these 15 countries received a more serious GHG emission reduction target, which is called the European Bubble. The burden sharing agreement (Council Decision 2002/358/EC) required these 15 countries to reach the GHG emission reduction target by the triptych approach, which is a sector-based $\mathrm{CO}_{2}$ emission allowance allocation principle that includes power sectors, energy intensive industries, and domestically-oriented sectors. Hence, we now examine whether it is helpful to improve the performances of these 15 countries through a cooperation and alliance.

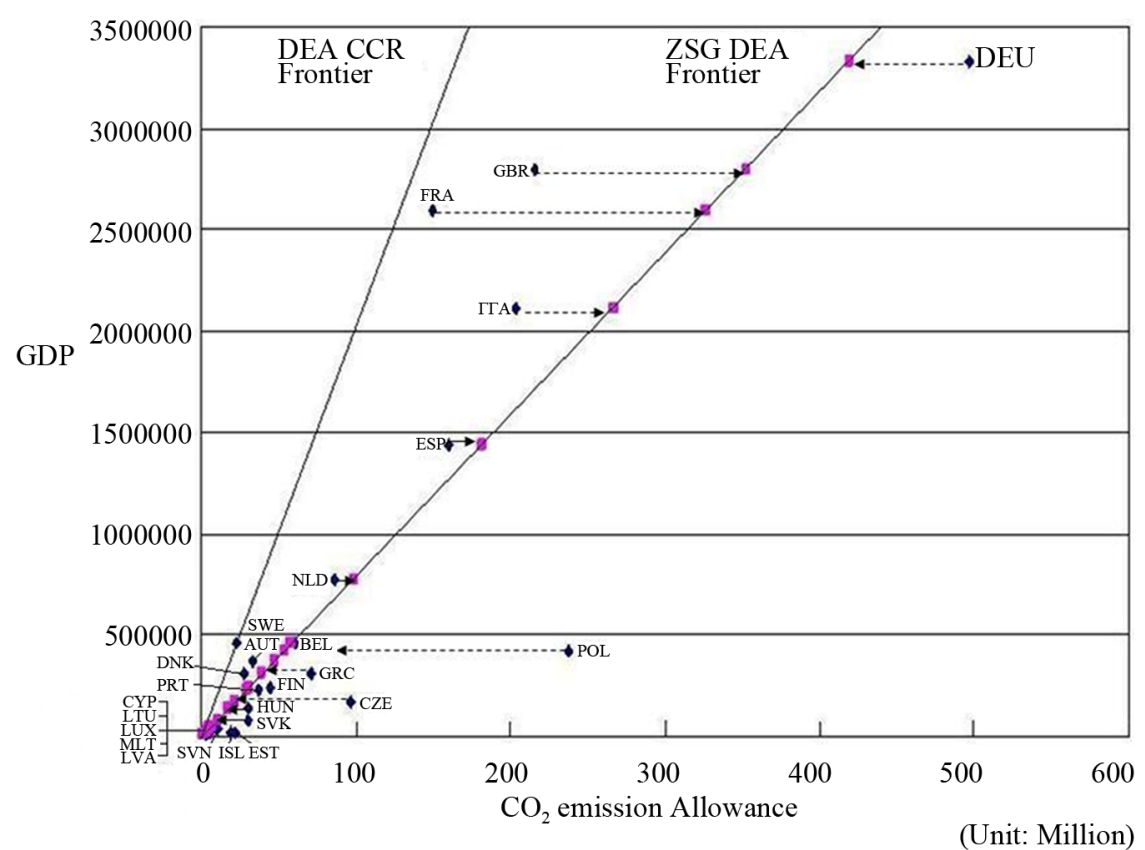

Figure 1. Efficiency in the DEA CCR model and the ZSG-DEA model.

\footnotetext{
${ }^{1}$ The G8 is a forum for the governments of eight of the world's largest economies including France, Germany, Italy, Japan, the United Kingdom, the United States, Canada, and Russia. The forum is organized by the former six countries above mention in 1975, thus leading to the name Group of Six (G6). The forum became the Group of Seven (G7) in the following year when Canada joined the forum. In 1997, Russia was added to group which then became known as the G8.
} 
The concept of performance by considering cooperation and alliance among DMUs originates from the ideal model in Gomes and Lins [10]. We let $\Omega$ be the cooperative DMUs' set, $q q^{g i}=c^{g} / c^{i}$ is the proportionality factor based on the proportional strategy, and $c^{g}$ and $c^{i}$ are the respective classical efficiency values of DMU $g$ and DMU $i$ that come from the DEA CCR model. In the regimes of the European Bubble and the burden sharing agreement, we assume that these 15 countries form a cooperation and alliance group. The efficiency values considering such cooperation among DMUs are presented as follows:

$$
\tau^{g^{\prime}}=c^{g}\left(1+\frac{\sum_{i=\Omega} z^{i}\left(1-q^{g i} \tau^{g^{\prime}}\right)}{\sum_{i=\Omega} z^{i}}\right)
$$

Equation (4) implies that the more states there are in a non-cooperation group, the lower their DMUs' efficiency values are. We next estimate all DMUs' efficiency values when 15 DMUs form an alliance. The results are in columns 4 and 5 in Table 2. After forming an alliance, the average performance in the CA model is superior to that in the DEA CCR model. We also see from the results of the CA model that the efficiency values of the DMUs increase in more than half of the $25 \mathrm{EU}$ member states. However, the efficiency values of four countries in the alliance group decrease. It is rather surprising that the performance of Sweden decreased from 100\% efficiency to becoming inefficient after forming an alliance. Although an alliance induces some countries' performances to deteriorate, it is still helpful to improve the average efficiency values no matter for all EU countries or for countries in the alliance. This result comes from comparisons between columns 3 with 4 and between columns 6 with 7 .

Table 2. DEA CCR efficiency in the CA model.

\begin{tabular}{|c|c|c|c|c|c|c|}
\hline Country & $\begin{array}{c}\mathrm{CO}_{2} \text { Emission } \\
\text { Allowance }\end{array}$ & $\begin{array}{l}\text { DEA CCR } \\
\text { Efficiency }\end{array}$ & $\begin{array}{c}\text { DEA CCR } \\
\text { Efficiency in the CA } \\
\text { Model }\end{array}$ & Efficiency Change & $\begin{array}{c}\text { DEA CCR } \\
\text { Efficiency before } \\
\text { Forming an Alliance }\end{array}$ & $\begin{array}{c}\text { DEA CCR } \\
\text { Efficiency after } \\
\text { Forming an Alliance }\end{array}$ \\
\hline Austria $^{\ddagger}$ & $32,729,289$ & 0.562 & 0.653 & + & 0.562 & 0.653 \\
\hline Belgium $^{\ddagger}$ & $60,428,821$ & 0.375 & 0.746 & + & 0.375 & 0.746 \\
\hline Cyprus & $5,899,493$ & 0.183 & 0.645 & + & -- & -- \\
\hline Czech Republic & $96,919,971$ & 0.089 & 0.384 & + & -- & -- \\
\hline Denmark $^{\ddagger}$ & $27,902,895$ & 0.550 & 0.660 & + & 0.550 & 0.660 \\
\hline Estonia & $21,343,525$ & 0.049 & 0.222 & + & -- & -- \\
\hline Finland $^{\ddagger}$ & $4,4620,371$ & 0.272 & 0.742 & + & 0.272 & 0.742 \\
\hline France $^{\ddagger}$ & $149,775,970$ & 0.856 & 0.500 & - & 0.856 & 0.500 \\
\hline Germany $^{\ddagger}$ & 497,302,479 & 0.331 & 0.754 & + & 0.331 & 0.754 \\
\hline Greece $^{\ddagger}$ & $71,162,432$ & 0.215 & 0.694 & + & 0.215 & 0.694 \\
\hline Hungary & $30,236,166$ & 0.227 & 0.708 & + & -- & -- \\
\hline Iceland $^{\ddagger}$ & $19,240,229$ & 0.052 & 0.235 & + & 0.052 & 0.235 \\
\hline Italy $^{\ddagger}$ & $203,255,077$ & 0.514 & 0.681 & + & 0.514 & 0.681 \\
\hline Latvia & $4,035,018$ & 0.352 & 0.752 & + & -- & -- \\
\hline Lithuania & $10,318,307$ & 0.187 & 0.652 & + & -- & -- \\
\hline Luxembourg $^{\ddagger}$ & $3,229,321$ & 0.784 & 0.533 & - & 0.784 & 0.533 \\
\hline Malta & $3,048,394$ & 0.122 & 0.496 & + & -- & -- \\
\hline Netherlands ${ }^{\ddagger}$ & $86,476,714$ & 0.445 & 0.718 & + & 0.445 & 0.718 \\
\hline Poland & $237,542,720$ & 0.088 & 0.381 & + & -- & -- \\
\hline Portugal $^{\ddagger}$ & $36,908,808$ & 0.309 & 0.753 & + & 0.309 & 0.753 \\
\hline Slovak Republic & $30,486,829$ & 0.136 & 0.537 & + & -- & -- \\
\hline Slovenia & $8,245,914$ & 0.283 & 0.747 & + & -- & -- \\
\hline Spain $^{\ddagger}$ & $159,739,872$ & 0.446 & 0.718 & + & 0.446 & 0.718 \\
\hline Sweden ${ }^{\ddagger}$ & $22,846,480$ & 1.000 & 0.443 & - & 1.000 & 0.443 \\
\hline United Kingdom ${ }^{\ddagger}$ & $215,875,184$ & 0.640 & 0.609 & - & 0.640 & 0.609 \\
\hline Average & & 0.363 & 0.599 & & 0.490 & 0.629 \\
\hline
\end{tabular}

${ }^{\ddagger} \mathrm{EU}$ state is in the European Bubble and the burden sharing agreement. 


\subsection{Market-Based Tool and Command-and-Control Regulation}

In previous subsection, we introduce the concept of $\mathrm{CO}_{2}$ emission allowance reallocation. Surplus or deficit allowances can be respectively sold or purchased based on the rule of the EU ETS, which requires a cap-and-trade program. The EU ETS regime makes $\mathrm{CO}_{2}$ emission allowance a tradable commodity. Thus, $\mathrm{CO}_{2}$ emission allowance is viewed as a market-based tool for reducing $\mathrm{CO}_{2}$ emissions. The previous subsection introduces cooperation and alliance among countries based on some international agreements in which the member states have to strictly comply to emission standards or implement particular technologies. Thus, cooperation and alliance is viewed as a command-and-control type regulation.

We now examine the effect of an environmental policy between the tradable allowance and the alliance among countries. By Figure 1, we have represented that the efficiencies of all DMUs can reach 100\% through trading of $\mathrm{CO}_{2}$ emission allowance. Although cooperation and alliance also improves the average efficiency values of all DMUs and the DMUs in the alliance, from Table 2 it cannot make the efficiency of all DMUs reach $100 \%$. Thus, we conclude that the environmental effect of a marketbased tool is superior to that of command-and-control regulation.

\section{Conclusions}

Environmental issues are not only becoming more and more important, but should also not be neglected, because many countries are conscious about global warming resulting from an increase in $\mathrm{CO}_{2}$ emissions. Both environmental researchers and social regulators have been using DEA to understand and solve the problem of global warming and climate change.

The EU has adopted both the $\mathrm{CO}_{2}$ mission allowance and an international agreement as two methods of $\mathrm{CO}_{2}$ emissions' reduction. In the EU ETS regime that requires a cap-and-trade program, surplus or deficit $\mathrm{CO}_{2}$ emission allowances can be respectively sold or purchased in a carbon market. Under the international agreement, some EU member states have formed a cooperation and alliance group, such as the European Bubble, to decrease $\mathrm{CO}_{2}$ emissions. Both of their aims are to reduce $\mathrm{CO}_{2}$ emissions and to prevent the global warming and climate change. We employ the ZSG-DEA model and the CA model to estimate the environmental effects of $\mathrm{CO}_{2}$ emission allowance and the international agreement, respectively. The result of this paper shows that the efficiencies of all DMUs can reach $100 \%$ after $\mathrm{CO}_{2}$ emission allowance reallocation by trading. Conversely, the international agreement only improves the average efficiency of all DMUs, but cannot make the efficiencies of all DMUs reach $100 \%$. Thus, the environmental effect of $\mathrm{CO}_{2}$ emission allowance is superior to that of the international agreement.

We lastly suggest a future improvement that considers a restricted undesirable output, such as the amount of $\mathrm{CO}_{2}$ emissions regulated by the social planner. One should note that how to model an undesirable output in a DEA context is presented in Dyckhoff and Allen as a reference [3].

\section{REFERENCES}

[1] J. P. M. Sijm, M. M. Beck, M. G. J. den Elzen and R. A. van den Wijnggarrt, "Options for Post-2012 EU Burden Sharing and EU ETS Allocation,” Netherlands Environmental Assessment Agency, Bilthoven, 2007.

[2] A. Charnes, W. W. Cooper and E. Rhodes, "Measuring the Efficiency of Decision-Making Units,” European Journal of Operational Research Vol. 2, No. 6, 1978, pp. 429444. doi:10.1016/0377-2217(78)90138-8

[3] H. Dyckhoff and K. Allen, "Measuring Ecological Efficiency with Data Envelopment Analysis (DEA)," European Journal of Operational Research, Vol. 132, No. 2, 2001, pp. 312-325. doi:10.1016/S0377-2217(00)00154-5

[4] T. C. Koopmans, "An Analysis of Production as an Efficient Combination of Activities,” In: T. C. Koopmans, Ed., Activity Analysis of Production and Allocation, Cowles Commission for Research in Economics, Wiley, New York, Monograph No. 13, 1951.

[5] H. Scheel, "Undesirable Outputs in Efficiency Evaluations,” Journal of Operational Research, Vol. 132, No. 2, 2001, pp. 400-410. doi:10.1016/S0377-2217(00)00160-0

[6] B. Golany and Y. Roll, "An Application Procedure for DEA,” Omega the International Journal of Management Science, Vol. 17, No. 3, 1989, pp. 237-250. doi:10.1016/0305-0483(89)90029-7

[7] C. A. K. Lovell, J. T. Pastor and J. A. Turner, "Measuring Macroeconomic Performance in the OECD: A Comparison of European and Non-European Countries,” European Journal of Operational Research, Vol. 87, No. 3, 1995, pp. 507-518. doi:10.1016/0377-2217(95)00226-X

[8] S. Rheinhard, C. A. K. Lovell and G. Thijssen, "Econometric Estimation of Technical and Environmental Efficiency: An Application to Dutch Dairy Farms,” American Journal of Agricultural Economics, Vol. 81, No. 1, 1999, pp. 44-60. doi:10.2307/1244449

[9] J. Sarkis and J. J. Cordeiro, “An Empirical Evaluation of Environmental Efficiencies and Firm Performance: Pollution Prevention versus End-of-pipe Practice,” European Journal of Operational Research, Vol. 135, No. 1, 2001, pp. 102-113. doi:10.1016/S0377-2217(00)00306-4

[10] E. G. Gomes and M. E. P. Lins, "Modelling Undesirable Outputs with Zero Sum Gains Data Envelopment Analysis Models," Journal of the Operational Research Society, Vol. 59, No. 5, 2008, pp. 616-623. doi:10.1057/palgrave.jors.2602384

[11] M. Coli, E. Nissi and A. Rapposelli, "Monitoring Environmental Efficiency: An Application to Italian Provin- 
ces,” Environmental Modelling \& Software, Vol. 26, No. 1, 2011, pp. 38-43. doi:10.1016/j.envsoft.2010.07.004

[12] L. M. Seiford and J. Zhu, "Modeling Undesirable Factors in Efficiency Evaluation,” European Journal of Operational Research, Vol. 142, No. 1, 2002, pp. 16-20. doi:10.1016/S0377-2217(01)00293-4

[13] R. Färe and S. Grosskopf, "Nonparametric Productivity Analysis with Undesirable Outputs: Comment," American Journal of Agricultural Economics, Vol. 85, No. 4,
2003, pp. 1070-1074. doi:10.1111/1467-8276.00510

[14] P. Marcos, E. Lins, E. G. Gomes, J. C. C. B. Soares de Mello and A. J. R. Soares de Mello, "Olympic Ranking Based on A Zero Sum Gains DEA Model," European Journal of Operational Research, Vol. 148, No. 2, 2003, pp. 312-322. doi:10.1016/S0377-2217(02)00687-2

[15] I. Sachs, "Understanding Development: People, Markets \& the State in Mixed Economies,” Oxford University Press, Oxford, 2000. 